\title{
COMMENT
}

\section{Multiple symbiotic partnerships are common in scleractinian corals, but not in octocorals: Comment on Goulet (2006)}

\author{
Andrew C. Baker ${ }^{1,2, *}$, Adrienne M. Romanski ${ }^{2}$ \\ ${ }^{1}$ Division of Marine Biology and Fisheries, Rosenstiel School of Marine and Atmospheric Science, University of Miami, \\ 4600 Rickenbacker Causeway, Miami, Florida 33149, USA \\ ${ }^{2}$ Department of Ecology, Evolution and Environmental Biology, Columbia University, MC 5557, 1200 Amsterdam Avenue, \\ New York, New York 10027, USA
}

\begin{abstract}
The ability of reef corals to adapt or acclimatize to projected climate change is a critical, but controversial, question in contemporary coral reef science and conservation. Much research has focused on whether or not corals are able to flexibly associate with diverse symbionts ('zooxanthellae') whose different physiologies may impart greater resistance to environmental extremes. Goulet (2006; Mar Ecol Prog Ser 321:1-7) concluded that most coral species only host zooxanthellae from a single Symbiodinium clade, and that these symbionts do not change in response to environmental disturbance, disease, or temperature stress. We re-evaluate her data and show that: (1) almost two-thirds of the coral species investigated have been severely undersampled $(\mathrm{N} \leq 5) ;(2)$ more than three-quarters of the scleractinian (stony) coral species sampled more adequately $(\mathrm{N}>10)$ host multiple Symbiodinium clades, or multiple types within a clade; (3) scleractinian corals are more flexible than octocorals; (4) almost all scleractinian coral families can host more than one symbiont clade. Moreover, the molecular approaches used by many studies are likely to have underestimated $S y m$ biodinium diversity, because they are unable to detect symbionts at low abundance and because they cannot distinguish between closely related types. In addition, various other studies show that: (1) scleractinian corals commonly host multiple symbiont types within a Symbiodinium clade; (2) symbiont communities in scleractinian corals are dynamic; (3) 'cryptic' symbiont taxa found at low abundance within colonies are unlikely to be molecular artifacts. We suggest that the majority of scleractinian coral species, including virtually all of the dominant reef-building taxa, can be found hosting multiple symbiont types, even at the clade level. This flexibility is important in understanding the past evolutionary success of these species and their future survival trajectories in the face of projected climate change.
\end{abstract}

KEY WORDS: Coral $\cdot$ Symbiodinium $\cdot$ Symbiosis $\cdot$ Climate change $\cdot$ Bleaching $\cdot$ Zooxanthellae Diversity

Resale or republication not permitted without written consent of the publisher

\section{Symbiont diversity within coral species is severely} undersampled

Goulet (2006) analyzed data on 442 coral species from 43 studies and found that 340 species $(77 \%)$ hosted Symbiodinium from only one clade. We compiled data from the same sources, but to avoid inflating the species count excluded coral species reported only to the generic level ('sp.' or 'spp.'), except where they could be unambiguously assigned to a single species not otherwise represented in the dataset. We also did not include T. L. Goulet et al. (unpubl.), for which no details were provided in Goulet (2006; see her Table 1, and references therein). Our analysis contained 307 
species, of which 230 (75\%) hosted only one clade. However, 64\% (198 of 307 species surveyed) were only sampled 5 times or less, including $73 \%$ (168 of 230 species) found to host only one clade (Table 1). Goulet's conclusion that 'most corals may not change their symbionts' is therefore based on an extremely limited sampling effort not reflected in her statement that sample sizes per species 'ranged from 1 to 565 with only $18 \%$ represented by a sample size of $1^{\prime}$ (p.3). In fact, when the analysis is restricted to the species for which sampling has been more significant $(\mathrm{N}>10)$, over two-thirds of all coral species (and almost threequarters of scleractinian coral species) host multiple symbiont types at the clade level or below (Table 1).

Field surveys of Symbiodinium have provided an overall picture of symbiont diversity on reefs at the expense of exploring diversity within host species. Fig. 1 illustrates the highly skewed distribution of sampling effort to date, and shows that it is inappropriate to draw conclusions regarding intra-specific symbiont diversity for all but the most broadly sampled coral species. Sampling of corals in unusual environments continues to reveal previously undocumented associations, even in relatively common and well-studied corals. Examples include Symbiodinium from Clade D in one colony of Colpophyllia natans sampled from a creek environment in the Florida Keys (A. C. Baker unpubl.) and an unusually deep and isolated colony of Acropora palmata in the Flower Gardens containing a Clade C symbiont (T. C. LaJeunesse unpubl.). Until coral species have been sampled in sufficient numbers, from diverse habitats, and across broad geographic and latitudinal ranges, only the most conservative conclusions regarding the absolute diversity of Symbiodinium found within single coral species can be made (Baker 2003).

\section{Flexibility in relative, not absolute, terms}

Although determining the absolute diversity of symbionts capable of associating with any particular coral species is problematic, comparisons of relative diversity among different coral taxa, when appropriately controlled for sampling effort, are still informative. These analyses should form the basis for comparing the relative flexibility of different coral species. Rather than ascribing flexibility to those species found, so far, to contain more than one clade, and inflexibility to those that have not, we suggest that a more accurate approach for assessing host flexibility is to standardize observed diversity against sampling effort.

Fig. 1 illustrates this principle for octocorals and scleractinian corals using the data sources listed in Goulet (2006), modified as described above. As sampling effort per species increases, the number of Symbiodinium clades documented also increases. Although we cannot use this approach to calculate a simple estimate of absolute diversity from literature sources (because more flexible coral species also tend to have attracted more sampling effort), it is nevertheless useful in highlighting relative differences in apparent flexibility between groups. Octocorals, for example, show relatively weak increases in symbiont diversity with increased sampling effort, while diversity recorded in scleractinian corals increases relatively rapidly. This indicates that scleractinian hosts are more flexible than their octocoral counterparts, but this difference is revealed only when $>10$ samples per species are collected. We hypothesize that this difference may be related to octocorals' greater dependence on heterotrophy compared to scleractinian corals (Fabricius \& Klumpp 1995), with octocorals consequently 
No. of Symbiodinium clades
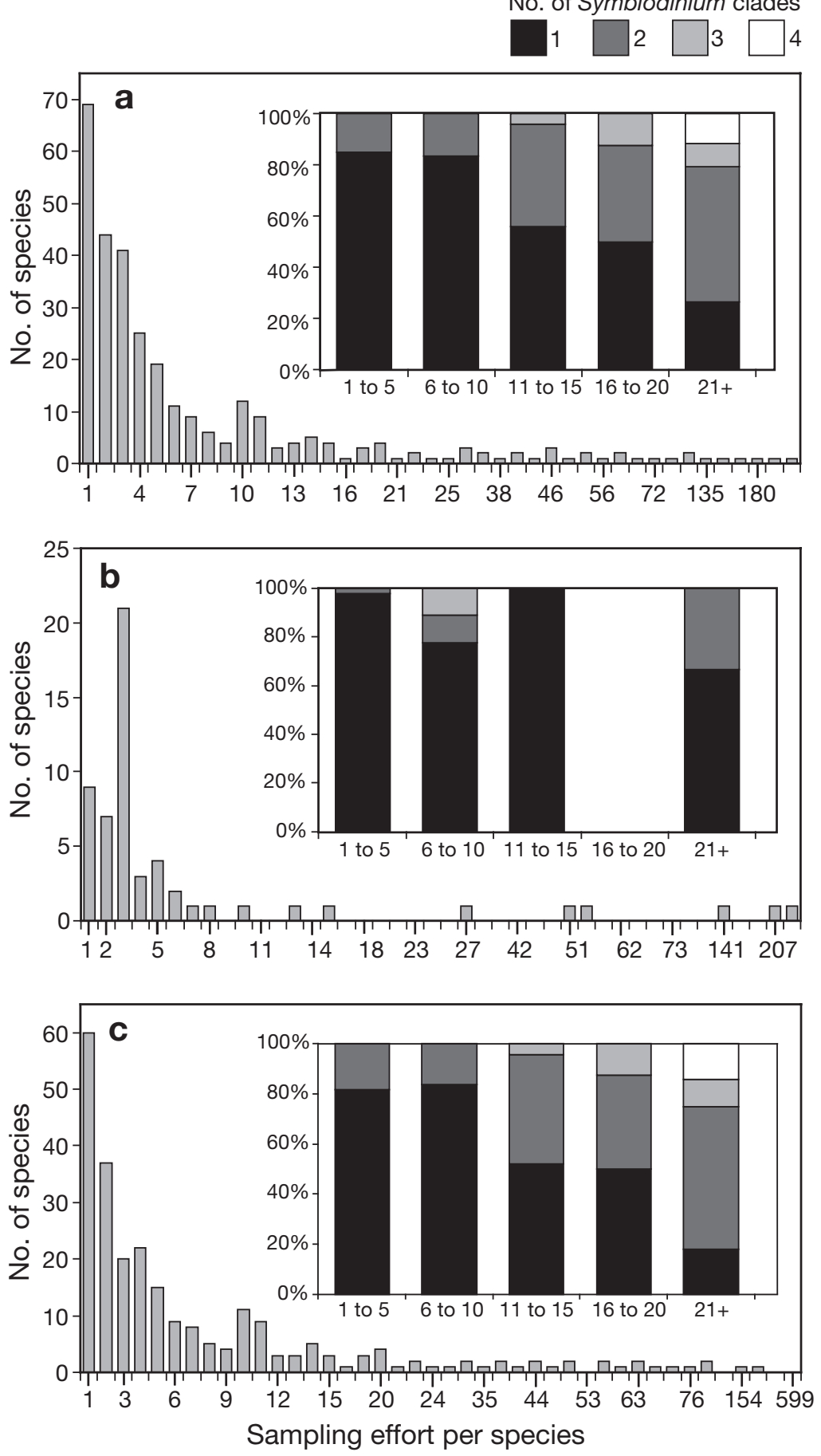

Fig. 1. Sampling effort per species for (a) all corals; (b) octocorals only; and (c) scleractinian corals only. All distributions are highly skewed to the left, revealing that most species are sampled few times. The same horizontal axis is used for all 3 panels, but tick marks and values along this axis are staggered across panels (a) to (c) to improve clarity. Inset panels show proportion of samples containing 1, 2, 3 or 4 Symbiodinium clades. As sampling effort increases (horizontal axis), a greater proportion of samples are revealed as hosting multiple clades. The number of clades detected increases with sampling effort faster in scleractinian corals than octocorals, indicating greater relative flexibility in the former compared to the latter having less to gain from retaining flexibility as a symbiotic trait (van Oppen et al. 2005b). Relative differences in autotrophy vs. heterotrophy may also help explain patterns of flexibility within the scleractinian corals.

Evolutionary considerations also support our conclusion that more coral species host multiple clades of Symbiodinium than have been documented to date. Table 2 shows that the vast majority of scleractinian families, including all of the dominant reef-building families (e.g. Faviidae, Acroporidae, Pocilloporidae, Poritidae), are able to host more than one clade, despite low sampling effort in some groups. Goulet's (2006) analysis assumes that different coral genera within the same family, and even different coral species within the same genus, show independent patterns of symbiotic association, with some species hosting multiple clades, and other closely related species hosting a single clade. For example, in our re-analysis of the data in Goulet (2006), 13 species of Acropora were recorded with symbionts in multiple clades (A, C and/or D jointly), while 33 species contained symbionts in only one clade (A, C or D separately). Goulet's interpretation of species data assumes that the ability to be flexible is a discrete evolutionary trait that has been gained (and/or lost) many times within genera. We think this is unlikely, and suggest that, although species vary in their relative flexibility, the patchy distribution of different symbiont taxa within many coral genera is more likely due to our failure to document the full range of symbiont diversity as a result of limited sampling of hosts and habitats. In the example of Acropora, we predict that, as more data are collected, it will become apparent that the genus (comprising $\sim 120$ species) is flexible to a much greater degree than the sparse dataset currently indicates.

\section{Many scleractinian coral species exhibit within-clade diversity}

Our re-analysis of the data in Goulet (2006) revealed that 47 of the 230 species (20\%) documented as hosting only one clade of Symbiodinium contained multiple types within that clade. However, this is again a substantial underestimate, because: (1) low sample sizes limit conclusions for many species; and 
Table 2. Distribution of Symbiodinium clades in scleractinian coral families. All families show diversity in their associations with symbionts in different clades, despite relatively low sampling effort in several families. The only exception is the Rhizangiidae, of which only 1 species, the temperate Astrangia danae, has been sampled to date

\begin{tabular}{|c|c|c|c|c|c|c|c|}
\hline \multirow{2}{*}{ Family } & \multirow[b]{2}{*}{ A } & \multirow[b]{2}{*}{ B } & \multicolumn{3}{|c|}{ Clade - } & \multirow{2}{*}{$\begin{array}{c}\text { No. of } \\
\text { species } \\
\text { sampled }\end{array}$} & \multirow{2}{*}{$\begin{array}{l}\text { Median no. } \\
\text { of samples } \\
\text { per species }\end{array}$} \\
\hline & & & $\mathrm{C}$ & $\mathrm{D}$ & $\mathrm{F}$ & & \\
\hline Acroporidae & $x$ & & $x$ & $\times$ & & 65 & 5 \\
\hline Agariciidae & & $x$ & $x$ & $x$ & & 24 & 3.5 \\
\hline Astrocoeniidae & $x$ & $x$ & $x$ & $x$ & & 8 & 5.5 \\
\hline Dendrophylliidae & $x$ & & $x$ & $x$ & & 5 & 2 \\
\hline Euphylliidae & & & $\times$ & $x$ & & 5 & 5 \\
\hline Faviidae & $x$ & $x$ & $x$ & $x$ & & 52 & 3 \\
\hline Fungiidae & $x$ & & $x$ & $x$ & & 12 & 2 \\
\hline Meandrinidae & $\times$ & $x$ & $\times$ & & & 4 & 2.5 \\
\hline Merulinidae & & & $x$ & $x$ & & 7 & 4 \\
\hline Mussidae & & $x$ & $x$ & $x$ & & 11 & 2 \\
\hline Oculinidae & & $x$ & $x$ & $x$ & & 4 & 8 \\
\hline Pectiniidae & & & $\times$ & $\times$ & & 6 & 2 \\
\hline Pocilloporidae & $x$ & & $\times$ & $x$ & & 10 & 9.5 \\
\hline Poritidae & $x$ & $x$ & $x$ & $x$ & $x$ & 25 & 6 \\
\hline Rhizangiidae & & $\times$ & & & & 1 & 11 \\
\hline Siderastreidae & & $x$ & $x$ & $x$ & & 11 & 5 \\
\hline
\end{tabular}

(2) many of the studies did not use molecular markers with sufficient resolution to detect significant withinclade diversity

Goulet's (2006) meta-analysis is missing at least 10 studies on the distribution and dynamics of Symbiodinium (LaJeunesse et al. 2004a, van Oppen 2004, Chen et al. 2005, McClanahan et al. 2005, van Oppen et al. 2005a,b, Huang et al. 2006, Magalon et al. 2006, Pochon et al. 2006, Thornhill et al. 2006a). Together with 8 more recent studies (Banaszak et al. 2006, Berkelmans \& Van Oppen 2006, Garren et al. 2006, Rotjan et al. 2006, Thornhill et al. 2006b, Ulstrup et al. 2006, Warner et al. 2006, Apprill \& Gates 2007), this literature is critical to a metaanalysis of coral flexibility, because these studies involve either large sample sizes within single coral species, a high diversity of sampled coral species and/or high resolution techniques suitable for detecting intra-clade diversity.

Of these 18 studies not included in Goulet's analysis, 15 investigated symbiont diversity using a fine-scale molecular marker (the internal transcribed spacer regions of nuclear ribosomal DNA, hypervariable regions in chloroplast 23S rDNA, or microsatellites); 13 of these studies documented coral species with intracladal symbiont diversity. Because significant physiological variability exists within clades (Savage et al. 2002, Tchernov et al. 2004), we cannot ignore the potentially critical role this diversity plays in understanding the physiological capacity of reef corals in response to environmental change.

\section{Stasis vs. change in coral species hosting one clade}

Goulet (2006) concludes that the majority of coral species host a single clade of Symbiodinium, and that these species exhibit fidelity in their algal genotypes over time, despite transplantation, disease or temperature stress. We suggest that the majority of scleractinian corals in fact host multiple clades, and that corals which host multiple clades shuffle the relative abundance of these symbionts in response to all of the factors listed by Goulet (e.g. Baker 2001, Glynn et al. 2001, Toller et al. 2001, Baker et al. 2004, Chen et al. 2005, Berkelmans \& van Oppen 2006, Thornhill et al. 2006a). Moreover, Goulet's conclusion that corals hosting only one clade exhibit algal fidelity is based on studies of only 4 scleractinian and 2 octocoral species (Goulet 2006, her Table 2). Of the scleractinian species, Fungia scutaria and Porites compressa were represented by a single individual sampled only once, after transplantation (LaJeunesse et al. 2004b,c), and Alveopora japonica hosts multiple clades (Rodriguez-Lanetty et al. 2002), and should not have been included.

In fact, when we include all the available literature, only 3 scleractinian species that have been found so far to host only a single clade (Pavona gigantea, Acropora millepora and Agaricia agaricites) have also been the subject of monitoring studies involving more than one individual (Iglesias-Prieto et al. 2004, Berkelmans \& van Oppen 2006, Thornhill et al. 2006b). These data are insufficient to support Goulet's overall conclusion that most corals are unable to change their algae. Studies of mixed-clade symbiont communities have shown these communities to be highly dynamic, and (as we argue here) these findings likely apply to the majority of scleractinian coral species.

\section{Cryptic symbionts are not artifacts}

Laboratory cultures of zooxanthellae can become dominated by types of Symbiodinium that are not representative of the dominant symbiont in the host from which they were originally isolated (Santos et al. 2001, LaJeunesse 2002). This indicates that algal symbiont communities in hospite include novel symbiont types whose relative numerical abundance is below the detection threshold of conventional PCR-based identification methods (typically 5 to $10 \%$ of the total symbiont community; Thornhill et al. 2006a). These 'cryp- 
tic' symbionts may be critical in providing corals with a greater capacity for symbiont 'shuffling' in response to environmental change (Baker 2003, 2004).

However, Goulet (2006) asserts that there is little or no evidence to support the existence of 'cryptic' symbionts in corals. She argues that unusual symbionts that emerge in culture from a coral source are not evidence of 'cryptic' zooxanthellae, because these symbionts have not been found to associate with that coral in nature, but she provides no alternative explanation for the origin of these unusual symbionts.

Goulet (2006) also argues that the molecular methods that have documented cryptic symbionts are prone to artifacts, and she cites cloning as a particular example of this. However, other molecular approaches, such as denaturing gradient gel electrophoresis, also commonly produce profiles indicating the presence of various unidentified symbiont taxa at background levels (e.g. LaJeunesse et al. 2004a). Moreover, Apprill \& Gates (2007) recently used cloning and sequencing to reveal dramatic background diversity in symbiont communities, and provide arguments supporting the authenticity of these findings. Finally, J. C. Mieog et al. (unpubl.) has used quantitative PCR to show that cryptic Symbiodinium, undetectable by conventional molecular methods, are common. These background symbionts are not in the same clade as the dominant type, and were documented even in a coral species (Acropora tenuis) not known to host multiple clades as an adult. Taken together, the evidence for the presence of background symbionts is overwhelming, and supports the conclusion that most field surveys published to date are extremely likely to have underestimated within-colony Symbiodinium diversity at all taxonomic levels.

\section{Conclusions}

Although there are a number of mechanisms by which reef corals (as symbioses between cnidarians and dinoflagellate algae in the genus Symbiodinium) might respond to climate change (Gates \& Edmunds 1999, Coles \& Brown 2003), most research has focused on whether or not corals are able to flexibly associate with diverse symbionts whose different physiologies impart greater resistance to environmental extremes (Buddemeier \& Fautin 1993, Rowan et al. 1997, Baker 2003, 2004, Baker et al. 2004, Berkelmans \& van Oppen 2006). Goulet (2006) has suggested that these findings are likely to apply to only a minority of coral species, but our re-analysis of the literature she cited indicates that she is incorrect to conclude that 'most corals host only one zooxanthella clade and do not change their algae, neither over time, nor after expo- sure to elevated temperatures, disease, or following transplantation' (p. 1). In fact, although some coral species do appear very specific in their associations with Symbiodinium (e.g. Rodriguez-Lanetty et al. 2006), corals as a group exhibit a range of flexibility, with the majority ( $\gg 50 \%$ ) of scleractinian coral species likely to be capable of hosting algal symbionts in different clades, as well as diverse symbionts within a single clade. Scleractinian corals are considerably more flexible than their octocoral counterparts, which may be related to their greater dependence on autotrophy.

There is no doubt that corals are severely threatened by the effects of climate change. However, Goulet's (2006) conclusion that 'the majority of coral species may not be able to switch symbionts and may be in greater peril than some studies imply' (p. 5) is not adequately supported by the data in her meta-analysis. We suggest that a more relativistic perspective, combined with an appreciation of the limited sampling undertaken to date, provides a more accurate picture of flexibility in coral-algal symbiosis and has important implications for understanding and predicting the future of reefs.

Acknowledgements. This work was supported by grants from the US National Science Foundation (OCE-0547169), the Wildlife Conservation Society and the Pew Institute for Ocean Science.

\section{LITERATURE CITED}

Apprill AM, Gates RD (2007) Recognizing diversity in coral symbiotic dinoflagellate communities. Mol Ecol 16: $1127-1134$

Baker AC (2001) Reef corals bleach to survive change. Nature 411:765-766

Baker AC (2003) Flexibility and specificity in coral-algal symbiosis: diversity, ecology, and biogeography of Symbiodinium. Annu Rev Ecol Evol Syst 34:661-689

Baker AC (2004) Diversity, distribution and ecology of Symbiodinium on coral reefs and its relationship to bleaching resistance and resilience. In: Rosenberg E, Loya Y (eds) Coral health and disease. Springer-Verlag, New York, p 177-194

Baker AC, Starger CJ, McClanahan TR, Glynn PW (2004) Corals' adaptive response to climate change. Nature 430: 741

Banaszak AT, Barba Santos MG, LaJeunesse TC, Lesser MP (2006) The distribution of mycosporine-like amino acids (MAAs) and the phylogenetic identity of symbiotic dinoflagellates in cnidarian hosts from the Mexican Caribbean. J Exp Mar Biol Ecol 337:131-146

Berkelmans R, van Oppen MJH (2006) The role of zooxanthellae in the thermal tolerance of corals: a 'nugget of hope' for coral reefs in an era of climate change. Proc R Soc Lond Ser B 273:2305-2312

Buddemeier RW, Fautin DG (1993) Coral bleaching as an adaptive mechanism-a testable hypothesis. BioScience 43:320-326

Chen CA, Wang AT, Fang LS, Yang YW (2005) Fluctuating algal symbiont communities in Acropora palifera (Sclerac- 
tinia: Acroporidae) from Taiwan. Mar Ecol Prog Ser 295: 113-121

Coles SL, Brown BE (2003) Coral bleaching-capacity for acclimatization and adaptation. Adv Mar Biol 46:183-223

Fabricius KE, Klumpp DW (1995) Widespread mixotrophy in reef-inhabiting soft corals: the influence of depth, and colony expansion and contraction on photosynthesis. Mar Ecol Prog Ser 125:195-204

Garren M, Walsh S, Caccone A, Knowlton N (2006) Patterns of association between Symbiodinium and members of the Montastraea annularis species complex on spatial scales ranging from within colonies to between geographic regions. Coral Reefs 25:503-512

Gates RD, Edmunds PJ (1999) The physiological mechanisms of acclimatization in tropical reef corals. Am Zool 39:30-43

Glynn PW, Maté Touriño J, Baker AC, Calderón MO (2001) Coral bleaching and mortality in Panamá and Ecuador during the 1997-1998 El Niño-Southern Oscillation event: spatial/temporal patterns and comparisons with the 19821983 event. Bull Mar Sci 69:79-110

Goulet TL (2006) Most corals may not change their symbionts. Mar Ecol Prog Ser 321:1-7

Huang H, Dong ZJ, Huang LM, Zhang JB (2006) Restriction fragment length polymorphism analysis of large subunit rDNA of symbiotic dinoflagellates from scleractinian corals in the Zhubi Coral Reef of the Nansha Islands. J Integr Plant Biol 48:148-152

Iglesias-Prieto R, Beltran VH, LaJeunesse TC, Reyes-Bonilla H, Thome PE (2004) Different algal symbionts explain the vertical distribution of dominant reef corals in the eastern Pacific. Proc R Soc Lond Ser B 271:1757-1763

Kirk NL, Ward JR, Coffroth MA (2005) Stable Symbiodinium composition in the sea fan Gorgonia ventalina during temperature and disease stress. Biol Bull 209:227-234

LaJeunesse TC (2002) Diversity and community structure of symbiotic dinoflagellates from Caribbean coral reefs. Mar Biol 141:387-400

LaJeunesse TC, Bhagooli R, Hidaka M, deVantier L, Done T, Schmidt GW, Fitt WK, Hoegh-Guldberg O (2004a) Closely related Symbiodinium spp. differ in relative dominance in coral reef host communities across environmental, latitudinal and biogeographic gradients. Mar Ecol Prog Ser 284:147-161

LaJeunesse TC, Lee S, Bush S, Bruno JF (2004b) Persistence of non-Caribbean algal symbionts in Indo-Pacific mushroom corals released to Jamaica 35 years ago. Coral Reefs 24:157-159

LaJeunesse TC, Thornhill DJ, Cox EF, Stanton FG, Fitt WK, Schmidt GW (2004c) High diversity and host specificity observed among symbiotic dinoflagellates in reef coral communities from Hawaii. Coral Reefs 23:595-603

Magalon H, Baudry E, Huste A, Adjeroud M, Veuille M (2006) High genetic diversity of the symbiotic dinoflagellates in the coral Pocillopora meandrina from the South Pacific. Mar Biol 148:913-922

McClanahan TR, Maina J, Moothien-Pillay KR, Baker AC (2005) Effects of geography, taxa, water flow, and temperature variation on coral bleaching intensity in Mauritius. Mar Ecol Prog Ser 298:131-142

Pochon X, Montoya-Burgos JI, Stadelmann B, Pawlowski J (2006) Molecular phylogeny, evolutionary rates, and divergence timing of the symbiotic dinoflagellate genus Symbiodinium. Mol Phylogenet Evol 38:20-30

Editorial responsibility: Howard Browman (Associate Editorin-Chief), Storebø, Norway
Rodriguez-Lanetty M, Cha HR, Song JI (2002) Genetic diversity of symbiotic dinoflagellates associated with anthozoans from Korean waters. Proc 9th Int Coral Reef Symp 1: 163-166

Rodriguez-Lanetty M, Chang SJ, Song JI (2003) Specificity of two temperate dinoflagellate-anthozoan associations from the northwestern Pacific Ocean. Mar Biol 143: 1193-1199

Rodriguez-Lanetty M, Wood-Charlson EM, Hollingsworth LL, Krupp DA, Weis VM (2006) Temporal and spatial infection dynamics indicate recognition events in the early hours of a dinoflagellate/coral symbiosis. Mar Biol 149:713-719

Rotjan RD, Dimond JL, Thornhill DJ, Leichter JJ, Helmuth B, Kemp DW, Lewis SM (2006) Chronic parrotfish grazing impedes coral recovery after bleaching. Coral Reefs 25: 361-368

Rowan R, Knowlton N, Baker AC, Jara J (1997) Landscape ecology of algal symbionts creates variation in episodes of coral bleaching. Nature 388:265-269

Santos SR, Taylor DJ, Coffroth MA (2001) Genetic comparisons of freshly isolated versus cultured symbiotic dinoflagellates: implications for extrapolating to the intact symbiosis. J Phycol 37:900-912

Savage AM, Trapido-Rosenthal H, Douglas AE (2002) On the functional significance of molecular variation in Symbiodinium, the symbiotic algae of Cnidaria: photosynthetic response to irradiance. Mar Ecol Prog Ser 244:27-37

Tchernov D, Gorbunov MY, de Vargas C, Yadav SN, Milligan AJ, Haggblom M, Falkowski PG (2004) Membrane lipids of symbiotic algae are diagnostic of sensitivity to thermal bleaching in corals. Proc Natl Acad Sci USA 101: 13531-13535

Thornhill D, LaJeunesse TC, Kemp D, Fitt WK, Schmidt G (2006a) Multi-year, seasonal genotypic surveys of coralalgal symbioses reveal prevalent stability or post-bleaching reversion. Mar Biol 148:711-722

Thornhill DJ, Fitt WK, Schmidt G (2006b) Highly stable symbioses among western Atlantic brooding corals. Coral Reefs 25:515-519

Toller WW, Rowan R, Knowlton N (2001) Repopulation of zooxanthellae in the Caribbean corals Montastraea annularis and $M$. faveolata following experimental and disease-associated bleaching. Biol Bull 201:360-373

Ulstrup KE, Berkelmans R, Ralph PJ, van Oppen MJH (2006) Variation in bleaching sensitivity of two coral species across a latitudinal gradient on the Great Barrier Reef: the role of zooxanthellae. Mar Ecol Prog Ser 314:135-148

van Oppen MJH (2004) Mode of zooxanthella transmission does not affect zooxanthella diversity in acroporid corals. Mar Biol 144:1-7

van Oppen MJH, Mahiny AJ, Done TJ (2005a) Geographic distribution of zooxanthella types in three coral species on the Great Barrier Reef sampled after the 2002 bleaching event. Coral Reefs 24:482-487

van Oppen MJH, Mieog JC, Sánchez CA, Fabricius KE (2005b) Diversity of algal endosymbionts (zooxanthellae) in octocorals: the roles of geography and host relationships. Mol Ecol 14:2403-2417

Warner ME, LaJeunesse TC, Robison JD, Thur RM (2006) The ecological distribution and comparative photobiology of symbiotic dinoflagellates from reef corals in Belize: potential implications for coral bleaching. Limnol Oceanogr 51: $1887-1897$ 